\title{
DISSEMINAÇÃO DE INOVAÇÕES E POLÍTICAS PÚBLICAS E ESPACGO LOCAL
}

\author{
Marta Ferreira Santos Farah*
}

RESUMIO

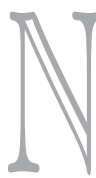

as últimas décadas, os governos locais, no Brasil, passaram por um processo de transformação caracterizado pela incorporação, por parte dos municípios, de novas atribuições e responsabilidades e pela introdução de inovações na administração pública local. Embora haja um número expressivo de pesquisas e trabalhos voltados à análise dessas transformações, há uma dimensão ainda negligenciada pela literatura. Trata-se do processo de disseminação de políticas públicas, de programas inovadores e de novas formas de gestão pública, processo segundo o qual uma inovação é reproduzida por outras localidades, ou, visto de uma outra perspectiva, de processo segundo o qual um município se inspira em iniciativas desenvolvidas anteriormente em outros locais. O objetivo deste capítulo é contribuir para a introdução do tema disseminação na agenda de pesquisa sobre gestão e poder local no Brasil, por meio da recuperação da literatura sobre difusão e disseminação de inovações e de políticas públicas e da discussão dos fatores que contribuem para a disseminação de políticas, programas e práticas de gestão inovadoras.

ABSTRACT

$\mathrm{n}$ the last decades, important changes occurred at the local level of government in Brazil, associated to the transfer of competences and responsibilities to the municipalities and related to the incorporation of innovations at this level of government. In spite of 1 an expressive number of researches with focus on these changes, there is still a lack of studies about the dissemination of public policies, innovative programs and innovations on public administration. Only recently some studies began to focus the analysis of the process by which an innovation is reproduced in another locality or, in another perspective, the process of adoption of innovations by a municipality based on an inspiration brought by similar initiatives in other localities. The purpose of this chapter is contribute to bring the theme of dissemination to the research agenda related to local government, local administration and local power in Brazil, through the analysis of the literature about diffusion and dissemination of innovations and public policies and through the discussion about the factors that explain the dissemination of innovative policies, programs and practices. 
disseminação ou difusão de políticas públicas não constitui um fenômeno novo. No entanto, nas últimas décadas, o processo de disseminação de políticas públicas tem se acentuado entre países e, no interior de um mesmo país, entre estados e municípios.

A intensificação da difusão ou disseminação de políticas públicas, a partir dos anos 80 do século $X X$, ocorreu sob o impacto, em primeiro lugar, da ocorrência significativa, nesse período, de eventos políticos que transcendem as barreiras nacionais, como a abertura econômica, o ajuste fiscal e a privatização (SUGYAMA, 2006; WEYLAND, 2004); e sob a influência de agências multilaterais e de instituições nacionais ou transnacionais hegemônicas. Em segundo lugar, essa intensificação ocorreu sob o impacto da crescente comunicação entre formuladores de políticas públicas, por meio de redes, cuja constituição foi facilitada por avanços tecnológicos (DOLOWITZ, 2000), que possibilitam a comunicação horizontal entre diversas pessoas e instituições simultaneamente, "atravessando" barreiras territoriais e espaciais e eliminando antigas barreiras temporais.

A intensificação da disseminação de políticas públicas no nível local de governo, por sua vez, dentro de um mesmo país, ou mesmo entre localidades situadas em diferentes nações, sofreu também o impacto da transferência para essa esfera de governo de atribuições e responsabilidades anteriormente concentradas no governo federal ou central.

Embora com grande variação de país para país, a descentralização constitui uma das "ondas" políticas do período recente, que veio reforçar a importância crescente da difusão de políticas no nível local de governo.

A análise do processo de difusão de políticas públicas pela literatura acadêmica tampouco é algo novo. Esse processo já fora objeto de pesquisas e de interesse acadêmico em períodos anteriores. Nas décadas de 60 e 70, autores como Crain (1966), Walker (1969) e Collier e Messick (1975) foram pioneiros na abordagem do tema, destacando que o estudo de tendências em políticas públicas e a análise da adoção de políticas públicas similares em diferentes localidades deveriam enfrentar o problema metodológico da interdependência ou do efeito da difusão. Assim, para explicar a decisão de adoção de uma determinada política pública não bastaria examinar fatores estruturais internos ao país ou localidade, mas seria necessário considerar, também, variáveis externas ligadas à difusão, como a proximidade espacial em relação a um lugar onde a política em questão já existisse (SUGYAMA, 2006).

Em que pesem estes e outros trabalhos pioneiros, o interesse pelo tema decresceu nos anos seguintes, sendo retomado a partir dos anos 90, sob impacto da intensificação do processo de disseminação nas últimas décadas. Autores como Rose (1991), Dolowitz e Marsh (1996 e 2000), James e Lodge (2003) e Weyland (2004) são alguns dos autores que, nos Estados Unidos e na Europa, reintroduzem o tema em estudos sobre políticas públicas no período recente.

A literatura sobre difusão de políticas públicas se filia a uma literatura mais abrangente que a precede, ou seja, a literatura sobre difusão de inovações. Rogers, autor que construiu sua teoria da difusão tendo como eixo o processo de comunicação entre membros de um sistema social, desenvolveu um dos primeiros trabaIhos de recuperação da pesquisa sobre difusão em diversos campos disciplinares, no início da década de 60 (ROGERS, 1995). Também o interesse pelo tema inovação e, conseqüentemente, por seu correlato, a difusão de inovações, sofreu um declínio após os anos 60, sendo retomado na década de 90 . Ao ser retomado, no entanto, parte expressiva da reflexão analítica sobre inovação e sobre difusão de inovações sofrera um "deslocamento de campo", passando a integrar o campo de estudos de políticas públicas e da administração pública. Focalizavam-se, agora, inovações em políticas públicas e na administração pública. A inovação tornara-se uma das "ondas" políticas que transcendem barreiras nacionais e barreiras entre governos subnacionais, e que envolvem, portanto, difusão ou disseminação. Den- 
tre os autores que retomam o estudo sobre difusão ou disseminação com essa perspectiva, incluem-se Berry e Berry (1990), Mintrom (1997) e Donahue (2005). Esses autores focalizaram, em seus estudos, a difusão de políticas inovadoras entre governos locais, considerando a difusão entre governos estaduais nos Estados Unidos. Outros autores tratam da difusão de políticas públicas entre países, observando a transferência de políticas entre países industrializados (CONDE, 2006), de países desenvolvidos para países em desenvolvimento (GALIMBERTI, 2005) e, num outro recorte, a disseminação de instituições e práticas de governança originárias tanto de países industrializados como de países em desenvolvimento (ADAMOLEKUN, 2005). Finalmente, parte da literatura recente sobre o tema trata da transferência de políticas públicas no quadro da Reforma do Estado, e tem como foco privilegiado países em desenvolvimento (WEYLAND, 2004).

No Brasil, a presença do tema da difusão, disseminação ou transferência de políticas públicas na produção acadêmica é ainda incipiente. Alguns trabalhos recentes incorporam o tema no quadro da discussão sobre Reforma do Estado (MELO, 2004). A análise da disseminação de políticas públicas no nível local de governo também é pouco explorada pela literatura, apesar da importância assumida por esse nível de governo no quadro do federalismo brasileiro pós-Constituição de 88 e da emergência de novas políticas públicas e de inovações na administração pública local, decorrentes das novas competências e responsabilidades assumidas pelos municípios nas últimas décadas. Alguns poucos trabalhos começaram a tratar do tema nos últimos anos (SUGYAMA, 2004 e 2006; WRAMPLER, 2004; PAULICS, 2003; FARAH, 2006a ${ }^{a} 2006$ b e 2006 c). Tais trabalhos pioneiros refletem, a exemplo do ocorrido em outros países, a intensificação do processo de disseminação de políticas públicas. Todos eles têm por referência a disseminação de políticas ou programas inovadores, ocorrida dos anos 90 para cá. Esses trabalhos procuram integrar à análise das determinações do desenvolvimento de políticas públicas a variável difusão. Na esfera local de governo, no Brasil, houve, no período recente, uma série de "ondas" de políticas públicas inovadoras, não sendo possível ignorar o efeito do processo de difusão sobre a constituição dessas ondas: de fato, a disseminação parece estar associada à ocorrência desta tendência de "repetição" em diversos locais de políticas públicas inovadoras.

Mas, em que pesem esses trabalhos, a discussão do processo de difusão ou disseminação constitui, ainda, uma lacuna na produção recente sobre a esfera local, com várias questões em aberto e com grande potencial de contribuição para o entendimento do local e de sua dinâmica hoje no Brasil, incluindo o desafio de integrar a essa reflexão a questão da diversidade regional.

A escassez de estudos sobre disseminação de políticas públicas e de inovações na gestão pública local chama a atenção, sobretudo, pela existência de uma já expressiva produção acadêmica de pesquisas sobre inovação no setor público, em todas as esferas de governo. Á semelhança do apontado por pioneiros no estudo de difusão de políticas públicas (CRAIN, 1966; WALKER, 1969; COLLIER e MESSICK, 1975 apud SUGYAMA, 2006), na análise de tendências em políticas públicas, é preciso considerar também variáveis externas, ligadas à difusão. Dito de outra forma, para entender o que ocorre hoje no local (nos diversos locais), é preciso incluir também, como fator explicativo, a influência que vem de fora, seja sob o efeito da proximidade espacial, seja por meio de redes horizontais, seja ainda como resultado da adoção por instituições supra-locais de mecanismos coercitivos ou de indução.

A importância atribuída à disseminação por atores engajados com a mudança na esfera local é evidenciada por diversas iniciativas que buscam dar visibilidade a inovações em políticas públicas e em práticas governamentais e não-governamentais, com foco na esfera pública local. Assim, no Brasil, desde que teve início - movimento de inovação na gestão pública subnacional associado à redemocratização, à descentralização e à "modernização" da esfera pública, podem ser identificadas iniciativas de difusão e disseminação. Na década de 80, uma das iniciativas pioneiras com esse objetivo foi a criação, no Estado de São Paulo, 
da RECEM - Rede de Comunicação de Experiências Municipais, pela Fundação Prefeito Faria Lima/CEPAM, durante o governo de Franco Montoro. Posteriormente, o Instituto Polis passou a publicar o Boletim Dicas, com o objetivo de difundir práticas inovadoras em gestão pública e em políticas públicas. O Programa Gestão Pública e Cidadania, criado em 1996, pela Fundação Getulio Vargas e pela Fundação Ford, também tem entre seus objetivos centrais a disseminação de políticas públicas e formas de gestão pública inovadoras, na esfera subnacional de governo. O Prêmio Itaú-UNICEF, criado em 1995, com foco específico na área de educação, desloca o objeto de disseminação de ações governamentais para programas e projetos não-governamentais: procura identificar e disseminar programas da sociedade civil desenvolvidos em caráter complementar à escola pública. Estes são apenas alguns exemplos do esforço de disseminação iniciado na década de 80 internamente ao país, com foco no espaço local. Também no âmbito federal, iniciativas de identificação e disseminação de políticas e programas foram instituídas, como o Prêmio Hélio Beltrão, promovido pela ENAP - Escola Nacional de Administração Pública, desde 1996.

Iniciativas similares, em âmbito internacional, têm também procurado disseminar inovações ou "best practices" promovidas por governos locais, com ênfase em países em desenvolvimento. A premiação de DUBAI (best practices) e a do Habitat, das Nações Unidas, constituem exemplos de uma verdadeira "política de disseminação", que não pode ser negligenciada por aqueles que estudam o espaço local.

Tais iniciativas revelam a importância atribuída à disseminação por parte de atores e instituições comprometidas com a transformação da administração pública e com a mudança nas políticas públicas implementadas pelo nível local de governo.

Esse tipo de atuação constitui, em si mesmo, um desafio à pesquisa e à reflexão sobre o tema. Em primeiro lugar, para subsidiar o próprio esforço de disseminação é preciso desenvolver trabalhos que estudem a eficácia das iniciativas de disseminação. Em segundo lugar, é importante refletir criticamente sobre o papel dos diversos agentes engajados no esforço de disseminação: a ação de algumas instituições e de redes de atores estaria impondo um projeto hegemônico de administração pública, como sugerem alguns trabalhos (COOKE, 2004; FARIA, 2006)?

Mas, é preciso ir além da reflexão centrada no papel de atores externos, pela relevância do tema disseminação para a compreensão do processo de formulação e implementação de políticas públicas. Nessa perspectiva, o papel dos atores locais ganha relevância na análise, que passa a reconhecer sua participação no processo de disseminação.

\section{(O) Conceito dle Difrusaro e Disseminação}

Para introduzir a discussão sobre disseminação no campo de estudos sobre governo local, é importante recuperar uma das principais questões abordadas pela literatura: a relativa ao próprio conceito de difusão ou disseminação. Não parece haver dúvida quanto ao fato de que o primeiro termo utilizado para fazer referência ao processo de adoção de políticas públicas por diferentes localidades foi o termo difusão.

Walkers (1969) e Crain (1966), por exemplo, citados como pioneiros na análise de difusão de políticas públicas, utilizam o conceito de difusão em seus trabaIhos. Crain, em seu estudo de 1966 sobre difusão de inovações entre cidades, recupera literatura sobre difusão de inovações anterior à década de 60 . Katz, Levin e Hamilton, citados por esse autor, assim definem o processo de difusão, em artigo de 1963, sobre as tradições de pesquisa a respeito da difusão de inovações:

Visto sociologicamente, o processo de difusão pode ser caracterizado como (1) a aceitação, (2) através do tempo, (3) de algum item específico - uma idéia ou prática, (4) por indivíduos, grupos ou outras unidades adotantes, ligados (5) a 
canais específicos de comunicação, (6) a uma estrutura social e (7) a um sistema de valores ou cultura (KATZ; LEVIN; HAMILTON, 1963, p. 240 grifo nosso) ${ }^{1}$.

Esses autores referem-se ao processo de difusão, tal qual analisado em diferentes campos de estudo, e mencionam a antropologia, a sociologia da comunicação, o campo da educação, da saúde pública e de marketing e a sociologia rural como disciplinas ou campos de estudo que, no início dos anos 60, já haviam tratado do tema difusão.

A definição proposta pelos autores resulta de uma sistematização elaborada a partir da literatura precedente, na qual, segundo eles, estão presentes um ou vários dos elementos indicados. Essa definição revela uma perspectiva bastante abrangente de difusão. Está ausente, no entanto, ao menos de forma explícita, a influência do processo político sobre a difusão. Não há referência tampouco à difusão de políticas públicas.

O clássico estudo de Rogers sobre difusão de inovações, de 1962, por sua vez, assim define difusão: "Difusão é o processo pelo qual uma inovação é comunicada, por intermédio de certos canais, através do tempo, aos membros de um sistema social. É um tipo especial de comunicação, no qual as mensagens dizem respeito a novas idéias" (ROGERS, 1995, p.5. grifo nosso).

A abordagem de Rogers (1995) enfatiza o processo de comunicação e a transmissão de informações como a base do processo de difusão. Embora o autor atribua um papel a indivíduos e organizações adotantes das inovações em sua teoria, no conceito de difusão enquanto tal, é enfatizada a dimensão comunicativa, a transmissão de conhecimento e de novas idéias ${ }^{2}$. Em sua obra, também se destaca a ausência de discussão dos processos políticos que presidem a difusão da inovação. Tampouco estava incorporada de forma explícita a discussão sobre a difusão de políticas públicas.

Rogers faz referência, ainda, à utilização, pela literatura, do termo disseminação, o adotado como referência em sessão temática do X Colóquio Internacional sobre Poder Local:

Alguns autores restringem o termo "difusão" ao processo espontâneo e não planejado em que idéias se espraiam, e usam o conceito de "disseminação" para a difusão que é dirigida e gerida. Neste livro, uso a palavra "difusão' para incluir tanto o processo espontâneo em que novas idéias se espraiam, como o processo planejado (ROGERS, 1995, p. 7 - grifo nosso)

Dentre os estudos que se voltaram ao estudo da difusão de políticas públicas nos anos 60, por sua vez, o estudo da difusão de inovações é entendido como a análise da:

...velocidade relativa e dos padrões espaciais de adoção de novos programas e políticas públicas, com ênfase na maneira com que organizações selecionam dentre soluções propostas aquelas que mais convergem com suas necessidades, e como estas organizações ficam sabendo de tais inovações (WALKER, 1969, p. 881 - grifo nosso).

No estudo de Walker (1969), é dada grande importância à análise do processo de decisão por parte do adotante, com a incorporação à análise de influências de teorias de decisão organizacional.

Um outro conceito utilizado pela literatura é o de lesson-drawing ${ }^{3}$ ou aprendizagem, proposto por Rose (1993). O autor utiliza esse conceito para se referir "ao

\footnotetext{
1 Tradução da autora deste e dos demais trechos de textos originais em inglês citados no trabalho.

2 Rogers, como já mencionado, elaborou sua teoria de difusão a partir de uma vasta investigação sobre a pesquisa a respeito do tema em diversos campos do conhecimento, tendo, em 1962, feito um inventário da produção anterior nos seguintes campos ou subcampos disciplinares: antropologia, sociologia, sociologia rural, educação, saúde pública e sociologia médica, comunicação, marketing e administração, geografia, sociologia geral, economia geral, administração pública e ciência política, economia agrícola, psicologia, engenharia industrial e estatística (ROGERS, 1995, p. 42-43).

3 O termo aprendizagem poderia ser utilizado em português, mas não deixa tão claro, quanto a expressão em inglês, o caráter voluntário envolvido na busca e seleção de lições pelo adotante.
} 
método segundo o qual se aprende a partir do passado ou de experiências externas à organização, enfatizando o papel dos burocratas e do programa enquanto tal no processo de aprendizagem" (ROSE,1993, p.6, apud EVANS, 2006). Esse conceito, de uso mais recente no campo da ciência política e dos estudos de políticas públicas, diz respeito ao processo voluntário de transferência, do qual o adotante participa de forma ativa.

Um conceito mais abrangente é o de policy transfer ou transferência de políticas públicas, introduzido nas últimas décadas no campo de estudos de políticas públicas.

Evans faz uma síntese interessante da literatura sobre transferência de políticas públicas, incluindo nessa síntese o próprio conceito de difusão:

\begin{abstract}
A análise da transferência de políticas públicas (public policy transfer analysis) é uma teoria do desenvolvimento de políticas públicas que procura entender um processo ou conjunto de processos segundo os quais conhecimentos acerca de instituições, políticas ou sistemas de provisão em um setor ou nível de política é usado no desenvolvimento de instituições, políticas ou sistemas de provisão de outro setor ou nível de governo. A literatura sobre transferência de políticas públicas pode ser organizada em duas escolas: uma que não usa esta designação "transferência de políticas públicas" diretamente, mas trata de diferentes aspectos de um processo de aprendizagem orientado para políticas públicas, usando diferentes nomenclaturas; e um que usa este conceito diretamente (EVANS, 2006, p. 480).
\end{abstract}

Dolowitz e Marsh são autores representativos dessa última escola, a que adota o conceito de policy transfer ou transferência de políticas públicas. Esses autores assim definem o processo de difusão-disseminação-transferência-aprendizagem (lesson drawing), tendo por referência políticas públicas:

Transferência de políticas públicas, emulação e lesson drawing referem-se todos a um processo segundo o qual conhecimento acerca de políticas públicas, arranjos administrativos, instituições etc..., em um tempo ou lugar, é usado no desenvolvimento de políticas, arranjos administrativos e instituições em outro tempo ou lugar (DOLOWITZ; MARSH, 1996, p. 344).

Esses autores reconhecem haver superposição entre os conceitos de difusão (e disseminação), aprendizagem (lesson drawing) e transferência de políticas públicas, mas afirmam sua preferência pelo último conceito, transferência, por o considerarem mais abrangente que o de aprendizagem - por incluir a transferência coercitiva - e por rejeitarem dois enfoques presentes em boa parte da literatura de difusão: de um lado, a visão da difusão como um processo sem sujeito e, de outro, o foco excessivo no processo enquanto tal, negligenciando o contexto e o conteúdo substantivo das políticas ou programas difundidos. No dizer de Dolowitz: "Não havia nenhum interesse... nos agentes envolvidos na difusão. O processo parecia ser um processo sem um sujeito, como se um processo espontâneo de formulação de políticas públicas fosse possível" (DOLOWITZ, 2000, p. 3).

Foi o mesmo tipo de consideração que levou à seleção do termo disseminação como referência para uma sessão temática do $X$ Colóquio de Poder Local e para este trabalho, ou seja, o propósito de tratar dos processos em questão como processos com sujeito (DOLOWITZ, 2000) e envolvendo intencionalidade (ROGERS, 1995). Há, assim, convergências entre esta opção e a que levou Dolowitz e Marsh (1996) a adotarem o conceito de transferência de políticas públicas. O termo disseminação, no entanto, oferece uma vantagem, a de abrir espaço para a inclusão, na produção sobre poder local, de análises referentes a iniciativas nãogovernamentais com impacto no espaço local. O conceito de transferência de políticas públicas (policy transfer), tal qual utilizado até o momento, tem uma inserção disciplinar bem definida e tende a dificultar a abertura de contribuições de outros campos ou de áreas interdisciplinares. 


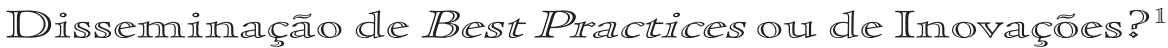

A análise recente sobre disseminação de políticas públicas e de instituições e práticas da administração pública trata da disseminação daquilo que se diferencia do "padrão" habitual de tratamento de problemas públicos. As iniciativas de disseminação de políticas e de práticas de gestão e as análises sobre o processo de disseminação interpretam de diferentes maneiras os objetos de disseminação. Estes têm sido entendidos ora como "melhores práticas", ora como inovações.

A análise do processo de disseminação ou difusão de políticas públicas requer, portanto, uma discussão preliminar dos conceitos de melhores práticas e de inovação. Na verdade, essa discussão é um passo necessário à construção de uma teoria do processo de disseminação.

O conceito de melhores práticas (best practices) foi introduzido no campo de estudos de administração pública e governo a partir da literatura de administração (management), especificamente da literatura sobre gestão da qualidade (MYERS; SMITH; MARTIN, 2004). Apesar da imprecisão do termo, utilizado atualmente em diferentes campos disciplinares, é possível identificar alguns elementos comuns à sua utilização, em diferentes áreas, os quais revelam a origem do termo no campo gerencial. Um desses elementos comuns é o foco no desempenho da organização, do programa, ou da política. Assim, por exemplo, documento de orientação aos participantes de reunião sobre transferência de melhores práticas na área pública, organizada pelas Nações Unidas em 2005, assim definia best practice: "um método superior ou uma prática inovadora que contribua para a melhoria do desempenho de uma organização; método ou prática esta reconhecida usualmente como 'melhor' por outras organizações" (UNDESA, 2005, p.5).

Um segundo elemento comum às diversas utilizações do termo best practices é o foco na técnica adotada para lidar com um problema ou desafio, sobretudo em uma técnica social (MYERS; SMITH; MARTIN, 2004).

Finalmente, um terceiro componente do conceito de melhores práticas, que interessa destacar aqui, é a idéia de modelo, algo a ser replicado em diferentes contextos. A replicabilidade de uma técnica social constitui um componente intrínseco do conceito de melhores práticas, que surgiu associado à idéia de melhoria da gestão (management): a melhoria ocorreria como resultado da adoção de best practices disponíveis, o que supõe, por sua vez, a comparação entre diferentes casos, em busca da melhor "fórmula" ou modelo.

O conceito de melhores práticas ou best practices implica uma visão de inovação como uma solução completa, fechada e integral, a qual, implicitamente, prescreve um modo específico e único de responder a um desafio ou problema. Da adoção de tal perspectiva resulta uma tendência a negligenciar a influência de diferentes contextos na formulação de cada solução - uma política pública, um programa, um novo modo de gestão ou arranjo institucional - e, ao mesmo tempo, o risco de se desconsiderar o processo que conduz à inovação.

Outra perspectiva, adotada neste trabalho, considera a inovação como a resposta a um desafio ou problema, que pode ser útil a outros, como parte de um repertório de alternativas a serem consideradas por aqueles que enfrentam problemas similares (FARAH, 2006b) ${ }^{5}$.

Uma resposta específica a um problema - a inovação -, nesta perspectiva, não é vista como uma solução fechada e completa, pronta para ser transferida para outras localidades, mas, sim, como algo em processo de transformação (FARAH, 2006b; FARAH, 2006c; PAULICS, 2003).

A inovação é, assim, um novo e bem sucedido arranjo particular de determinados componentes, uma condensação temporária de componentes, que pode

\footnotetext{
${ }^{4}$ Os tópicos 3 a 5 deste trabalho são uma versão revista de trabalho apresentado ao X Colóquio de Poder Local (FARAH, 2006 c).

${ }_{5}^{5}$ Sobre o conceito de inovação e sobre inovação em governos subnacionais, ver também Jacobi e Pinho (2006).
} 
ser potencialmente útil em outros contextos e localidades, como solução para um problema específico (FARAH, 2006b). Nesse sentido, o componente prescritivo característico da noção de modelo é abandonado, adotando-se, em seu lugar, a perspectiva de uma alternativa a ser considerada por aqueles que tomam a decisão sobre políticas e programas em outras localidades.

A técnica social passa, assim, a ser apenas um dos aspectos que explicam o sucesso da inovação, tão importante quanto aspectos do contexto em que se deu a formulação e a implementação da política ou programa (SPINK, 2000; SPINK, 2006).

De forma complementar, a inovação passa a ser entendida como o resultado de um processo de criação coletiva que não se encerra com sua adoção em determinado local (original), sendo antes uma solução aberta, para cuja construção contribuem todos os que a adotam, por meio de mudanças incrementais e constantes.

Tendo por base tal conceito de inovação (e não o de melhores práticas/best practices), é que se discutem, neste trabalho, os fatores que contribuem para a disseminação ou difusão de políticas públicas e programas governamentais.

\section{Fartores qure Determinam o Processo dle Disseminaçăo}

Quais os fatores que explicam a disseminação de uma inovação? Se se adota a perspectiva melhores práticas-replicação, o foco da análise recai sobre a inovação enquanto tal e sobre suas características, isto é, supõe-se que a difusão dependa essencialmente de características intrínsecas de cada inovação. É a característica do modelo que determina se a política pública ou programa governamental poderá ser adotada em outra localidade.

Na perspectiva que vê inovação como uma alternativa dentre um repertório de possibilidades, a importância do contexto é enfatizada pela análise, no sentido de que é a localidade ou município "adotante" que define as características da inovação que pode adotar. O termo disseminação é mais adequado a tal abordagem do que o termo replicação. Este último sugere a reprodução de um modelo. $O$ termo disseminação, por sua vez, sugere uma perspectiva mais horizontal, a qual inclui a seleção ativa e a incorporação de idéias e práticas por outros ${ }^{6}$. A perspectiva das melhores práticas-replicação tende a atribuir um papel passivo à localidade receptora, enquanto a perspectiva da inovação-disseminação pretende reconhecer a participação ativa das localidades ou municípios adotantes no processo de adoção de inovações e mesmo na sua "recriação", reatualizando a inovação.

Indicam-se, a seguir, com base na abordagem inovação-disseminação, fatores que devem ser considerados na análise do processo de disseminação de políticas e programas.

\section{Características intrínsecas da inovação}

O primeiro fator que contribui para que uma política ou programa se dissemine consiste em características intrínsecas à política ou programa inovador relacionadas à sua capacidade de dar uma resposta efetiva a problemas e desafios enfrentados por uma administração ou governo. Sendo uma inovação, trata-se da capacidade de dar uma resposta a novos problemas ou de dar uma resposta a velhos problemas de uma forma nova e bem sucedida.

\footnotetext{
${ }^{6}$ Dolowitz e Marsh (1996) propõem o termo "policy transfer" ou transferência de políticas públicas em substituição ao termo difusão. Segundo esses autores, a literatura sobre difusão prevalece à visão da "transferência" de políticas como um processo espontâneo e sem sujeito. Ao adotar o conceito de transferência, esses autores procuram chamar a atenção para a ação de agentes ou atores na "disseminação" ou "difusão" de políticas. A proposta de utilização do termo disseminação no presente trabalho teve o mesmo propósito de destacar o papel de atores no processo de difusão, com ênfase nos atores das unidades "receptoras" (uma expressão que ainda merece revisão, por sugerir passividade). Ver, também, trabalho de Rose sobre a transferência voluntária de políticas públicas, definida por este autor como lesson drawing ou aprendizagem (ROSE, 1991).
} 
Segundo Marsh e Dolowitz (1996), estudos sobre difusão de políticas públicas desenvolvidos nos anos 60 e 70, ao focalizarem o processo de difusão, considerando aspectos como tempo, proximidade geográfica e semelhança de recursos, acabaram negligenciando os conteúdos específicos das políticas. Estudos desenvolvidos por analistas de políticas públicas a partir da década de 80 procuraram superar esta lacuna, incorporando a dimensão substantiva das políticas, seu conteúdo, à análise do processo de "transferência de políticas" (ibid).

$\mathrm{Na}$ perspectiva adotada neste trabalho, considera-se o conteúdo da política ou programa um elemento central à análise. A capacidade que uma política, programa ou processo tem de constituir-se em solução inovadora para problemas sociais (KINGDON, 1995) é condição para sua disseminação para outras localidades.

No caso brasileiro, iniciativas selecionadas por programa de premiação de inovações em governos subnacionais, o Programa Gestão Pública e Cidadania, podem ser consideradas ilustrativas dessa capacidade de responder a problemas e desafios enfrentados por governos locais, atendendo, assim, a um dos condicionantes básicos do processo de disseminação ${ }^{7}$.

\section{Natureza do problema enfrentado pela política ou programa inovador}

Uma segunda característica relevante para a análise do potencial de disseminação de uma inovação é a natureza do problema enfrentado. Se o problema "tratado" pela inovação é comum a outras localidades, a inovação tem, em princípio, o potencial de ser útil a estas outras localidades ou municipalidades (FARAH, 2006d). Se o problema é peculiar a uma localidade, a inovação tenderá a ser uma resposta específica, com reduzido potencial de disseminação. Trabalho de Donahue, sobre a difusão de inovações em governos estaduais nos Estados Unidos, chama a atenção para esse fator na análise do processo de disseminação. Esse autor (DONAHUE, 2005) propõe uma tipologia de modelos de inovação em políticas públicas estaduais que afetam o processo de disseminação. Um dos modelos propostos por este autor é o modelo idiossincrático, caracterizado por inovações sob medida, desenvolvidas para realidades específicas, o que constitui uma barreira à sua adoção por outros estados (ibid).

Dentre os programas finalistas do Programa Gestão Pública e Cidadania ${ }^{8}$, todas as políticas ou programas desenvolvidos originalmente em um município, estado ou comunidade indígena (ou simultaneamente em mais de um local) respondem a problemas comuns a diversas localidades. Na verdade, esse foi um dos critérios de seleção adotados (http://inovando.fgvsp.br). Assim, em princípio, todos teriam potencial de disseminação.

Podem ser citados, como exemplos, o Programa Bolsa-Escola/Renda Mínima e o Programa Saúde da Família. O primeiro foi implementado de forma inovadora, simultaneamente, em meados da década de 90, em duas localidades distintas - em Brasília, Distrito Federal, e no município de Campinas, em São Paulo, como iniciativa de dois partidos políticos distintos (PT e PSDB). Tal iniciativa tem por objetivo a concessão de uma renda básica a famílias de baixa renda, condicionando o acesso a esse benefício à garantia de ingresso na escola de crianças de sete a 14 anos. O programa Saúde da Família, por sua vez, estrutura a atenção à saúde de forma integral e com foco na família, articulando o atendimento ambulatorial ao acompanhamento das famílias em

\footnotetext{
7 Consideram-se, aqui, os programas finalistas - 200 iniciativas selecionadas entre 1996 e 2006 - ao longo de processos seletivos que envolveram pesquisadores e "práticos" engajados na gestão pública subnacional em diversas áreas da administração e de políticas públicas. Esses programas foram reunidos em publicações, reunindo os 20 finalistas de cada ano, as quais se encontram disponíveis no site http://inovando.fgvsp.br. Ver, por exemplo, Spink e Clemente (1997), Farah e Barboza (2000) e Teixeira, Godoy e Clemente (2005).

\& 200 programas selecionados entre 1996 e 2006.
} 
seu local de moradia. Em ambos os casos, se tratam de respostas a carências básicas nas áreas de educação e saúde, presentes em todos os municípios brasileiros, e que, portanto, tinham, em princípio, o potencial de se disseminarem, o que de fato ocorreu. Num primeiro momento, a disseminação se deu de forma horizontal, de município para município e por meio de redes, constituídas por partidos, políticos, servidores públicos, comunidades profissionais e movimentos sociais ligados aos setores de educação e de saúde. Num segundo momento, o governo federal transformou essas inovações em programas nacionais, implementados e geridos no nível municipal, o que fortaleceu o processo de disseminação ${ }^{9}$. Os programas citados, aqui, como exemplos são alguns dos selecionados pelos trabalhos pioneiros no estudo da disseminação de políticas públicas no nível subnacional no Brasil (SUGIYAMA, 2004; WAMPLER, 2004; PAULICS, 2003; PAULICS, 2006).

\section{Percepção da relevância do problema ou desafio}

A existência de um problema similar em locais distintos da localidade onde a iniciativa foi implantada pela primeira vez não constitui um fator suficiente para que a disseminação ocorra. A inovação tenderá a ser adotada por outros municípios se os atores sociais e políticos dessas localidades considerarem os problemas tratados pela inovação como problemas relevantes, como problemas sociais que requerem uma resposta e a busca de soluções inovadoras (KINGDON, 1995; FUCKS, 2000).

Esse fator chama a atenção para a importância de atores internos às localidades receptoras no processo de disseminação de políticas e programas. Nos casos mencionados, a disseminação de um município a outro se baseou não apenas no fato de diversos municípios compartilharem situações sociais comuns, mas na percepção comum dessas situações como problemas sociais: a pobreza, a educação e a saúde são percebidas como questões sociais relevantes pelas localidades adotantes.

\section{Convergência com a agenda de políticas públicas de diferentes localidades}

Um quarto fator consiste na existência de convergência entre o problema tratado pela política ou programa inovador e a agenda de políticas públicas de diferentes localidades (KINGDON, 1995; FUCKS, 2000). Nesse caso, é maior a probabilidade de a inovação ser selecionada pelos atores envolvidos no processo de formulação e implementação de políticas e programas, nas localidades.

A título de ilustração, pode ser citado o programa Pingo d'Água, de Quixeramobim, no Ceará, localizado no semiárido brasileiro. Essa iniciativa foi reproduzida em diversos municípios da região Nordeste, também afetados pelo problema da seca, segundo depoimento do responsável pelo programa: "[o programa Pingo d'Água] foi desenvolvido em pelo menos 87 dos 100 municípios mais afetados pela seca no Ceará, e também em outras municipalidades do semiárido, em outros estados" (Entrevista Pingo d'Água, 2004).

Esse caso ilustra bem a presença dos quatro fatores cruciais ao processo de disseminação mencionados até aqui: a capacidade de responder a um problema social, a existência de um problema comum a diversas localidades; o reconhecimento da situação ou condição como problema social e, finalmente, sua inclusão na agenda governamental e de decisão (KINGDON, 1995) das localidades receptoras.

A agenda local, por sua vez, é influenciada por um conjunto de fatores que condicionam, portanto, de forma indireta, o processo de disseminação:

\footnotetext{
9 Um aspecto do processo de disseminação, cuja análise ultrapassa o escopo deste trabalho, diz respeito às transformações introduzidas na inovação "original", como ocorreu, por exemplo, quando o programa Bolsa-Escola foi transformado no programa Bolsa-Família pelo governo federal, durante o governo Lula.
} 
Fatores estruturais, tais como a globalização e a crise fiscal, os quais estabelecem novos desafios aos governos subnacionais. Assim, por exemplo, passaram a ganhar relevância na agenda local, nas últimas décadas, temas como geração de emprego e renda e desenvolvimento local;

A influência de agências externas, sobretudo de agências de financiamento, por meio de mecanismos indutivos, tais como condicionalidades no acesso a recursos e de estratégias de difusão em fóruns internacionais. A incorporação da variável ambiental e da questão de gênero pelas ações governamentais constitui exemplo de temas e abordagens sugeridos por agências financiadoras que influenciam a agenda local (de diferentes "locais");

$\S \quad$ A redefinição de atribuições dos municípios no quadro do federalismo brasileiro, pós-88. A agenda local sofreu fortemente o impacto dessa redefinição, ganhando maior relevância a problemática social;

$\S \quad$ A influência de atores sociais e de políticos internos, como políticos, burocratas, especialistas e movimentos sociais de cada localidade. Há um processo de decisão no nível da localidade receptora que intervém no processo de construção da agenda e da formulação de políticas públicas locais. Esse processo decisório inclui a seleção de alternativas de políticas e a "busca" de opções em outras localidades. O processo interno à localidade adotante é parte fundamental do processo de disseminação.

É importante reconhecer a influência da agenda local no processo de disseminação para evitar a perspectiva que ignora o contexto das localidades adotantes. Se, nessas localidades, a agenda local não enfatiza determinados temas, as características intrínsecas da inovação tornam-se, no limite, irrelevantes: a municipalidade não quer a inovação, pois ela não diz respeito a uma questão social e política relevante naquele contexto específico, ou, ainda, a sua adoção não é considerada prioritária no quadro mais abrangente de ação governamental, tendo em vista um balanço entre recursos mobilizados e resultados a serem obtidos. Assim, embora o tema possa integrar a agenda sistêmica (KINGDON, 1995), isto é, embora seja reconhecido localmente, por atores sociais e políticos locais, como um problema social, ele pode não ter um status suficiente para integrar a agenda de governo e, sobretudo, a de decisão, isto é, a que inclui as questões que serão objeto de ação governamental efetiva.

Depoimento a respeito da não ocorrência de disseminação de um dos programas selecionados como finalista pelo Programa Gestão Pública e Cidadania é bastante interessante neste sentido. O responsável pelo programa Escola Pantaneira, desenvolvido em Aquidauana, no Pantanal, relata que, apesar do esforço de disseminação do programa, esta não ocorreu, pois as localidades potencialmente adotantes decidiram pela não adoção da iniciativa:

Recentemente houve uma tentativa [de disseminação ]... Eles [O Instituto Parque do Pantanal] tentaram levar a experiência a outros municípios; fizeram uma proposta orientada à ampliação do programa, incluindo estas outras localidades. Mas a proposta não foi aceita pelos municípios, porque eles [IPP] queriam que as municipalidades colocassem recursos financeiros e eles queriam entrar apenas com recursos administrativos (Entrevista Escola Pantaneira, 2003, grifo nosso).

\section{Acesso a informação}

A disseminação de inovações é, também, dependente da existência de informação, que pode ser difundida por intermédio de uma relação direta entre o município inovador e outras localidades, a partir de relações de vizinhança (WALKER, 1969; BERRY e BERRY, 1990 apud WAMPLER, 2004; SUGYAMA, 2004) ou de semeIhanças entre as localidades envolvidas (WEYLAND, 2004). Análise sobre programas finalistas do Programa Gestão Pública e Cidadania no período 1996-2003, 
revela que, dentre os programas municipais que se disseminaram sem a indução de níveis mais abrangentes de governo, 56,8\% obedeceram ao efeito vizinhança apontado pela literatura. (FARAH, 2006 a).

O depoimento de um entrevistado a respeito da iniciativa do processo de disseminação do programa Universalização do Ensino em Icapuí, no Ceará, ilustra a transmissão de informações entre as próprias localidades, nesse caso, pelo efeito de vizinhança ou proximidade: "[a iniciativa foi] do governo do município de Fortim, por meio dos canais de comunicação estabelecidos entre os dois municípios, porque eles estão geograficamente na mesma área, a qual enfrenta os mesmos desafios" (Entrevista Universalização do Ensino).

Contudo, a difusão de informação, freqüentemente, ocorre por meio de redes compostas seja por um tipo específico de participante (burocratas, especialistas, prefeitos, ONGs, partidos políticos etc...), seja por uma composição de diferentes tipos de atores (SUGIYAMA, 2004), deixando a informação de ser transmitida diretamente pelo inovador aos receptores potenciais.

Nesse processo de divulgação "indireta" da informação, por meio de redes, ocorre a participação de atores e instituições externas às localidades envolvidas. Destacam-se, nesse sentido, programas de premiação de âmbito internacional como o Habitat, das Nações Unidas, e o de Melhores Práticas, de Dubai, cujo propósito é divulgar informações sobre políticas, programas ou práticas em diversas áreas ligadas ao desenvolvimento econômico e social e à melhoria de condições de vida. No Brasil, como visto anteriormente, as primeiras iniciativas com o objetivo de tornar públicas e acessíveis informações sobre políticas, programas ou práticas inovadoras governamentais datam das décadas de 80 e 90 (MATTOS, 2004). A primeira dessas iniciativas foi a RECEM - Rede de Comunicação de Experiências Municipais, criada pelo CEPAM - Fundação Prefeito Faria Lima. Em documento de lançamento da Rede, é explícita a importância atribuída ao acesso à informação:
A Rede de Comunicação de Experiências Municipais - RECEM - é um sistema dedicado à coleta, documentação e disseminação de informações referentes a experiências alternativas e inovadoras de iniciativa de poderes municipais ou de grupos sociais e comunidades do país, e à geração de conhecimento que pos- sam funcionar como apoio a decisões de planejamento e administração munici- pal (FUNDAÇÃO PREFEITO...., 1988 grifo nosso).

Dentre outras iniciativas com objetivo similar, destacam-se o Boletim Dicas, do Instituto Polis, o Prêmio Gestão Pública e Cidadania, da Fundação Getulio Vargas e da Fundação Ford, e o Prêmio Prefeito Criança, da Fundação Abrinq, todas com foco no nível local de governo.

A divulgação de informações por meio de iniciativas como as indicadas se diferencia da transmissão direta da informação pelo inovador para outras localidades, caracterizando-se por um processo que envolve redes sociais (SUGYAMA, 2004; SUGYAMA, 2006) e uma "terceira parte", não diretamente envolvida no desenvolvimento ou na adoção da política ou programa (WEYLAND, 2004). Weyland, analisando o processo de difusão de modelos de reforma política na América Latina, afirma que a intervenção dessa "terceira parte" no processo de disseminação tem a vantagem de ampliar o horizonte de inovações, trazendo experiências de locais não diretamente em contato com o país receptor. Mas, esse mesmo autor aponta como tal participação, sobretudo no caso de organizações internacionais, traz o risco de que soluções uniformes sejam "empurradas" para diversos países, sem respeito a suas condições específicas (WEYLAND, 2004, p. 14). As observações de Weyland a respeito da disseminação de modelos de reforma política chamam a atenção para potencialidades e limites da participação de atores externos, no processo de divulgação de informações sobre inovações que podem ser adaptadas à análise da disseminação de inovações em níveis subnacionais de governo.

Ainda a respeito da informação como fator relevante para o processo de disseminação, é importante considerar que alguns analistas, ao enfatizarem o acesso à informação, tendem a ver a disseminação como um processo estritamen- 
te cognitivo. Segundo Marcus Melo, "em muitos estudos sobre a influência de modelos cognitivos, a difusão de políticas aparece simplesmente como um problema de tornar disponível o conhecimento" (MELO, 2004, p.4, grifo nosso). Embora o acesso seja uma importante condicionante do processo de disseminação, não é fator suficiente, sendo fundamental não negligenciar outros aspectos aqui mencionados, em especial o indicado a seguir, relativo à influência da decisão de atores locais.

\section{Seleção de inovações por atores envolvidos no processo decisório nas localidades receptoras}

A disseminação de inovações na área pública é condicionada por um papel ativo desempenhado por atores sociais e políticos nas localidades adotantes. Isto significa que as condições mencionadas até aqui são importantes, mas não suficientes para que a disseminação ocorra.

Atores sociais e políticos internos agem para incorporar uma determinada inovação - podendo também rejeitá-la ou ignorá-la - influenciando, assim, o processo de disseminação. Essa participação ativa de atores locais é apontada por Marcus Melo:

O mimetismo, dessa perspectiva, é visto não como um mecanismo automático, como em muitos estudos de difusão, mas como representando uma escolha. De fato, atores domésticos, em processo de difusão, perseguem ativamente modelos de políticas e, também, usam atores externos de forma estratégica (MELO, 2004, p. 7).

Tal ação não se dá, é preciso destacar, num vazio institucional e estrutura. Elaé condicionada por fatores de contexto mencionados anteriormente e pela própria existência de informação. Mas outros elementos são relevantes, definindo constrangimentos institucionais e estruturais à decisão por parte das localidades receptoras:

\section{Incentivos políticos}

A adoção de uma inovação pode ser influenciada por incentivos políticos, o que significa que é afetada pelos benefícios políticos, os quais a inovação potencialmente trará (SUGYAMA, 2004; CONDE-MARTINEZ, 2005)). Essa perspectiva é a privilegiada pela abordagem da escolha racional, que enfatiza o cenário competitivo, opondo partidos e políticos em uma democracia (WALKER, 1969, apud SUGYAMA, 2004). Assim, a inovação será adotada se for vista como um meio para a reeleição. Pesquisa recente de Natasha Sugyama $(2004,2006)$ revela, no entanto, que esse fator tem reduzido poder explicativo no processo de disseminação de políticas e programas inovadores no nível subnacional de governo no Brasil. Analisando o processo de disseminação dos programas Bolsa-Escola/Renda Mínima e Saúde da Família, essa autora afirma: "Surpreendentemente, as proxies para competição política ofereceram pouco apoio ao argumento de que a competição eleitoral e o comportamento orientado para a busca de voto por parte de políticos favoreceram a reprodução de políticas públicas" (SUGYAMA, 2006, p. 26).

\section{Incentivos financeiros}

A adoção de determinadas políticas e programas pela esfera local de governo tende a ser influenciada pela existência de incentivos financeiros, vindos do governo federal, mas, também, provenientes de agências multilaterais e de ONGs (ibid, 2004). No Brasil, a incorporação de inovações pelo nível local de governo é influenciada por transferências financeiras feitas pelo governo federal, associadas à implementação pelos governos locais de políticas e programas específicos. Este é o caso, por exemplo, dos programas de Saúde da Família e Mãe Canguru, na área de saúde, que surgiram como iniciativas locais e se transformaram, posteriormente, em programas federais, condicionados à adoção "voluntária" de gover- 
nos municipais, "beneficiários" da possibilidade de acesso a recursos federais. Outro exemplo é o programa de qualificação de professores do ensino fundamental, estimulado pela criação do FUNDEF - Fundo de Manutenção e Desenvolvimento do Ensino Fundamental e de Valorização do Magistério; o acesso ao Fundo, por parte dos municípios, é condicionado à alocação de $60 \%$ dos recursos em programas de qualificação de professores.

A mesma influência se faz sentir no caso do apoio de ONGs e agências multilaterais ao desenvolvimento de programas governamentais locais. Há diretrizes e condicionalidades no acesso a recursos que acabam por induzir a adoção de determinadas "inovações".

\section{Quadro institucional}

A seleção de uma política ou programa inovador por parte de atores locais pode ser facilitada ou dificultada por características do quadro institucional existente no país e na própria localidade (FARAH, 2006a). No Brasil, muitos dos programas inovadores e das novas instituições e arranjos organizacionais, no nível subnacional de governo, tiveram um importante estímulo no quadro institucional estabelecido a partir da Constituição de 1988, no nível federal. Tal é o caso da adoção de programas inovadores de atenção a Crianças e Adolescentes, estimulada no nível local de governo pela regulação federal, consubstanciada no Estatuto da Criança e do Adolescente, e pela atribuição às esferas subnacionais, pela Constituição de 88 , da coordenação e execução de programas nessa área. O mesmo ocorre na área da saúde, na qual iniciativas inovadoras orientadas para a abordagem preventiva e para a integração de diferentes níveis de atenção estão fortemente ligadas à estrutura institucional federal, consubstanciada no Sistema Único de Saúde - SUS. A existência desse quadro institucional pode ser entendida como um incentivo à adoção de inovações coerentes com os princípios estruturadores do arcabouço federal.

\section{Características estruturais da localidade receptora}

A adoção de uma inovação depende da existência de capacidade administrativa e de recursos diversos que viabilizem a adoção da política ou programa e sua adaptação às condições locais.

Algumas iniciativas requerem, por exemplo, capacidade de mobilização de recursos por parte do município, exigência que pode restringir o leque de localidades com capacidade para adotar determinada inovação. Esse tipo de restrição ocorre, inclusive, em casos em que está presente a indução federal por meio de incentivos financeiros. Análise de Lena Lavinas mostra como, em proposta do governo federal referente à adoção de programas de renda mínima na década de 90, de 5.507 municípios, apenas 251 poderiam arcar com a contrapartida financeira local prevista na implantação do programa, o qual contaria com recursos federais (LAVINAS, 1998 apud SOUZA, 1999).

As características da inovação determinam os requisitos de capacitação e de recursos das localidades receptoras. No caso do programa Licenciamento Ambiental para Redes de Infra-Estrutura Urbana, de Porto Alegre, Rio Grande do Sul, por exemplo, é interessante refletir sobre o fato de o responsável pelo programa não ter informações sobre a disseminação do programa. A ausência de disseminação ${ }^{10}$ decorre, muito provavelmente, em primeiro lugar, do fato de tratar-se de uma problemática que integra a agenda governamental de poucos locais, de características similares à de Porto Alegre, como algumas regiões metropolitanas do país. Além disso, a disseminação para essas localidades requereria a existência de atributos institucionais e de recursos técnicos relativamen-

${ }^{10}$ A ausência de informação sugere ausência de disseminação ou disseminação restrita. 
te complexos, além de recursos financeiros que poucos municípios poderiam mobilizar, restringindo ainda mais o leque de potenciais adotantes.

\section{Legado de políticas prévias}

A decisão sobre a seleção e adoção de determinada política, de um repertório de alternativas disponíveis, é também afetada por padrões prévios consolidados em cada campo de política pública, em um país, em um estado e nos municípios. Assim, a probabilidade de uma política inovadora se disseminar e o ritmo da disseminação tendem a ser afetados por este legado de cada campo. Não há, ainda, no entanto, estudos empíricos que levem em consideração esse fator.

\section{Ideologia}

A adoção (ou rejeição) de inovações na área pública pode, também, ser afetada por um processo de seleção ideológica de alternativas, como apontado por Sugiyama (2004 e 2006)), em análise sobre programas inovadores no Brasil. Segundo a autora:

[...] políticos e seus administradores são fortemente orientados por suas crenças ideológicas e estas freqüentemente limitam o espectro de suas escolhas políticas e prioridades. Cidades governadas por prefeitos da direita, tipicamente enfatizam políticas públicas que encorajam os interesses ligados a negócios, seja por meio de investimentos em infra-estrutura, seja por meio de programas que estimulem a competição do mercado.... Políticos da esquerda tendem a enfatizar programas sociais em suas campanhas e em suas políticas [...] (SUGYAMA, 2004).

A análise de Natasha Sugyama é baseada em estudo do processo de disseminação de dois programas sociais - Bolsa Escola-Renda Minima e Programa Saúde da Família. Seu estudo confirmou a importância de fatores ideológicos na adoção dos programas. É importante, no entanto, incluir como desafio para futuras análises o fato de a agenda definida em um campo ideológico influenciar a agenda do outro campo. Assim, programas surgidos em governos de filiação ideológica à esquerda - como o orçamento participativo, tornado conhecido pela experiência de Porto Alegre - difundiram-se para diversos municípios, em administrações de diferentes partidos. Do mesmo modo, iniciativas orientadas para a criação de um ambiente de negócios ou para a eficiência do gasto acabaram por ser adotadas por administrações de partidos à esquerda.

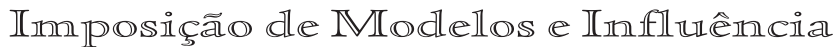 dle Arores e Institurições Locaris}

Na análise do processo de disseminação, assume particular importância o aspecto relativo à imposição de agendas e de políticas e programas por atores externos ao local. Este constitui um ponto de intersecção importante entre os estudos sobre disseminação e difusão e a perspectiva de Estudos Críticos em Administração.

Autores filiados a essa perspectiva têm alertado para a influência exercida por agências multilaterais em países do Terceiro Mundo, destacando a dimensão de poder implícita em teses e propostas apresentadas como técnicas e neutras. Dito de outra forma, apresenta-se como modelo a ser adotado por tais países propostas e abordagens que se inserem em uma concepção de desenvolvimento e de administração pública, concebida "no centro". Haveria, segundo essa perspectiva, uma imposição de modelos, por meio da cooptação dos tomadores de decisão nos países em desenvolvimento. Cooke e Borges, em estudos recentes, afirmam que a disseminação da participação como elemento central da administração pública em países em desenvolvimento, nas últimas décadas, decorre de 
uma "imposição" do Banco Mundial, ator que influencia fortemente a agenda e a prática governamental nesses países (COOKE, 2004; BORGES, 2003). A influência de atores externos sobre o espaço local é apontada, também, por Faria, Iamasato e Guedes (2006), em estudo sobre a influência da estratégia empresarial em município da região Nordeste, apresentado no X Colóquio Internacional de Poder Local. Nesse estudo, os autores defendem a tese de que a estratégia de grandes corporações exerce grande influência sobre o espaço local, por meio da disseminação de modelos e de instrumentos de gestão. Esses modelos e instrumentos de gestão acabam sendo hegemônicos no local, influenciando tanto a ação de organizações privadas, como públicas.

A influência sobre a agenda e as ações privadas e públicas no espaço local não se limita à exercida por agências multilaterais e grandes corporações privadas, por meio da disseminação de modelos e best practices, coerentes com as estratégias desses atores. Há estudos que apontam a influência sobre o espaço local da disseminação de modelos como resultado de um processo político de transformação de uma experiência em paradigma ou modelo a ser adotado por outros. Assim, Novaes, por exemplo, em trabalho apresentado no X Colóquio de Poder Local, analisa a construção teórica do modelo de Barcelona, como processo político que buscava possibilitar a disseminação desse modelo.

A perspectiva que destaca a imposição de modelos chama a atenção para a dimensão política (relativa a poder) implícita nos processos de disseminação e destaca a capacidade desigual de influenciar a agenda dos diversos atores que participam do processo de formulação de políticas públicas e de construção de consensos sobre práticas de gestão pública e privada no espaço local. Mas, freqüentemente, essa perspectiva tende a ver toda disseminação ou difusão de políticas públicas e de práticas de gestão como imposição de modelos. Ao mesmo tempo, essa perspectiva tende a atribuir sempre ao modelo uma eficácia que supõe no receptor ou adotante, uma incapacidade de interferência, uma passividade que o desqualifica como ator, como participante ativo de processos decisórios, de processos políticos (FARAH, 2006).

Análise desenvolvida por MARTINEZ (2006 sobre transferência de políticas públicas reconhece a existência de processos de transferência em que a imposição prevalece. Mas essa seria uma das modalidades de transferência, a que geralmente ocorre em programas de apoio ao desenvolvimento, sob forte influência de financiadores externos. Além da ressalva apontada por Conde, é importante, também, chamar a atenção para a existência sempre de atores locais, adotantes ou receptores. A análise concreta de processos de disseminação deve estar atenta para a influência exercida por diversos atores na adoção da inovação no local, escapando, assim, da visão simplificadora que vê em qualquer disseminação uma imposição. Como visto neste trabalho, os atores locais têm um papel e uma voz nesse processo.

\section{Cornsidleratções Firnais}

A disseminação de políticas públicas e programas governamentais constitui o leit motiv de diversas instituições e atores, que procuram estimular a divulgação de informações sobre inovações ou sobre o que consideram best practices, como forma de promover a "reprodução" de políticas bem sucedidas. Partidos políticos, agências multilaterais, ONGs, universidades, redes de profissionais de determinado campo de ação governamental, como saúde e educação, participantes de movimentos sociais, têm participado de esforços nesse sentido. Níveis mais abrangentes de governo, por sua vez, têm induzido a "reprodução" de programas por intermédio da concessão de recursos condicionada à adoção de determinados modelos de ação.

Ainda que essa ação pró-disseminação seja hoje expressiva, a análise do processo de disseminação ainda é incipiente no país, sobretudo no que se refere aos governos subnacionais, em especial à disseminação de políticas e programas no nível municipal. 
Procurou-se neste artigo contribuir para a introdução do tema no campo de estudos sobre o local no Brasil, por meio da recuperação da literatura, com ênfase na literatura recente sobre disseminação de políticas públicas, destacando, nesta recuperação, a discussão sobre o conceito de disseminação e o questionamento do conceito de melhores práticas (best practices). O artigo procura, como subsídio para a análise do processo de disseminação no espaço local no Brasil, construir um referencial analítico, identificando os principais fatores a serem considerados na análise do processo de disseminação.

O referencial adotado enfatiza o papel exercido pelas localidades adotantes no processo de disseminação. As localidades adotantes, nessa perspectiva, exercem um papel ativo, participando da decisão relativa à adoção da política ou programa. A disseminação depende, portanto, não apenas de características intrínsecas da política ou programa, ou de um processo estritamente cognitivo, associado ao acesso à informação, mas da relação entre a inovação (política ou programa) e o contexto em que esta será implementada; sob a influência de atores e instituições externas (e de seu papel indutor, de fornecedor de informação, dentre outros), mas, também, de atores e instituições internas ao local que adota a inovação.

Referê̂mcials

ADAMOLEKUN, Ladipo. Transferability of governance institutions: the Ombudsman and the Independent Commission against Corruption. In: UNDESA. Innovations in Governance and Public Administration: replicating what works. United Nations. Department of Economic and Social Affairs. New York, 2006. p. 85-94. (Adriana Alberti and Guido Bertucci (org.). http://www.unpan1.un.org/

BERRY, Francês Stokes; BERRY, William D. State lottery adoptions as policy innovations: an event history analysis. American Political Science Review, v. 84. n. 2, 395-415, 1990.

BORGES, André. Governança e política educacional: a agenda recente do Banco Mundial. Revista Brasileira de Ciências Sociais, vol.18, n. 52, Junho 2003.

COLLIER, David; MESSICK, Richard E. Prerequisites versus diffusion: testing alternativa explanations of Social Security adoption. The American Political Science Review, v. 69, n.4, 1299-1315, 1975.

CONDE MARTINEZ, Carlos. Different approaches to policy transfer. In: UNDESA. Innovations in Governance and Public Administration: replicating what works. United Nations. Department of Economic and Social Affairs. New York, 2006. (Adriana Alberti and Guido Bertucci (org.). http://www.unpan1.un.org/

COOKE, Bill. O gerenciamento do (Terceiro) Mundo. Revista de Administração de Empresas, v.44, n.3, julho/setembro 2004.

CRAIN, Robert L. Fluoridation: diffusion of an innovation among cities. Social Forces, v.44, n.4, Jun. 1966, p. 467-476.

DOLOWITZ, David P. Introduction. Governance: an International Journal of Policy and Administration, vol. 13, n. 1, January 2000, p. 1-4.

DOLOWITZ, David P.; MARSH, David. Learning from abroad: the role of policy transfer in contemporary policy-making. Governance: an International Journal of Policy and Administration, vol. 13, n. 1, , p. 5-24.

DOLOWITZ, David P.; MARSH, David. Who learns what from whom? A review of the policy transfer literature. Political Studies, n, 44, p. 343-357, 1996

DONAHUE, John D. Dynamics of diffusion: conceptions of American federalism and essential readings. Upper Saddle River, NJ, Prentice Hall, 2005. 
EVANS, Mark. At the interface between theory and practice - Policy transfer and lesson drawing. Review of "Learning from comparative Public Policy: a practical guide", by Richard Rose. Public Administration, v. 84, n.2, p. (479-515, 2006,

FARAH, Marta Ferreira Santos; BARBOSA, Hélio Batista. Novas experiências de gestão pública e cidadania. Rio de Janeiro: Editora Fundação Getulio Vargas, 2000.

FARAH, Marta Ferreira Santos. Dissemination of innovations: learning from subnational awards programmes in Brazil. In: UNDESA. Innovations in Governance and Public Administration: replicating what works. United Nations. Department of Economic and Social Affairs. New York, 2006 (Adriana Alberti and Guido Bertucci (org.). http://www.unpan1.un.org/ (2006 a).

FARAH, Marta Ferreira Santos. Dissemination of local programs and policies in Brazil: the contribution of the Public Management and Citizenship Program. Paper delivered at the 2006 Meeting of the Latin American Studies Association LASA 2006. San Juan, Puerto Rico, March 15-18, 2006 (2006 b).

FARAH, Marta Ferreira Santos. Disseminação de políticas públicas e programas governamentais no nível subnacional de governo. In: COLÓQUIO INTERNACIONAL DE PODER LOCAL: DESENVOLVIMENTO E GESTÃO SOCIAL DE TERRITÓRIOS, 10., 2006, Salvador. Anais... Salvador: UFBA/CIAGS, 2006, BA, CD-ROM. (2006 c).

FARAH, Marta Ferreira Santos. Inovação e governo local no Brasil contemporâneo. In: JACOBI, Pedro; PINHO, José Antonio (org.). Inovação no campo da gestão pública local: novos desafios, novos patamares. Rio de Janeiro: Editora FGV, 2006. p. 41-77. (2006 d)

FARIA, Alexandre; IMASATO,Takeyoshi; GUEDES, Ana Lúcia. Administração estratégica e poderes locais: as corporações e sua influência na produção e disseminação de conhecimentos em estratégia. In: COLÓQUIO INTERNACIONAL DE PODER LOCAL: DESENVOLVIMENTO E GESTÃO SOCIAL DE TERRITÓRIOS, 10., 2006, Salvador. Anais... Salvador: UFBA/CIAGS, 2006, BA, CD-ROM. (2006).

FUKS, Mario. Definição da agenda, debate público e problemas sociais: uma perspectiva argumentativa da dinâmica do conflito social. In: Bib, n.49, $1^{\circ}$ sem. 2000, p. 79-94.intradoc/groups/public/documentos/UN/UNPAN021963.pdf.

FUNDAÇÃO PREFEITO FARIA LIMA - CEPAM. Municípios em busca de soluções: Boletim RECEM. São Paulo, 1986.

FUNDAÇÃO PREFEITO FARIA LIMA - CEPAM/RECEM. Ambiente construído. São Paulo, 1988. Série Acervo, n.1

GALIMBERTI, Joseph. Adaptation of best practices: the experience of the Institute of Public Administration of Canada. In: UNDESA. Innovations in Governance and Public Administration: replicating what works. United Nations. Department of Economic and Social Affairs. New York, 2006. p. 85-94. http:// www.unpan1.un.org/

JACOBI, Pedro; PINHO, José Antonio. Inovação no campo da gestão pública local: novos desafios, novos patamares. Rio de Janeiro: Editora FGV, 2006.

JAMES, Oliver; LODGE, Martin. The limitations of 'Policy Transfer' and 'Lesson Drawing' for public policy research. Political Studies Review, 2003, v.1, p. 179-193.

KATZ, LEVIN; HAMILTON, 1963. Traditions of research in the diffusion of innovation. American Sociological Review, v. 28, April 1963, p.237-258.

KINGDON, John W. Agendas, alternatives, and public policies. New York: HarperCollins, 1995. 2nd ed.

LAVINAS, Lena. Políticas sociais descentralizadas: limites dos programas de 
renda mínima e bolsa-escola. In: ENCONTRO ANUAL DA ANPOCS, 22., 1998, Caxambu, MG, Anais... Caxambu, MG: ANPOCS, 1998.

LATOUR, Bruno. Ciência em ação. São Paulo: Editora Unesp, 2000.

MATTOS, Janaína Valéria de. Programas de disseminação de experiências de governos locais no Brasil em contexto de redemocratização e de descentralização. 2004. Dissertação (Mestrado em Administração Pública e Governo)- Programa de Mestrado e Doutorado em Administração Pública e Governo FGV-EAESP. São Paulo, 2004.

MELO, Marcus André. Escolha institucional e a difusão dos paradigmas de política: o Brasil e a segunda onda de reformas previdenciárias. Dados, v. 47, n. 1, 2004, Rio de Janeiro.

MINTRON, Michael. Policy entrepreneurs and the diffusion of innovation. American Journal of Political Science. v. 41, n.3, p.7738-770, 1997.

MYERS, Stephanie; SMITH, Hayden; MARTIN, Lawrence. Conducting best practices research in public affairs. Central for Community Partnerships, College of Health \& Public Affairs, University of Central Florida. Working paper, 2004.

PAULICS, Veronika Anna Theodora. Disseminação do Programa de Garantia de Renda Mínima no Brasil (1991-1997). Dissertação (Mestrado em Administração Pública e Governo). Escola de Administração de Empresas de São Paulo, Fundação Getulio Vargas, São Paulo, 2003.

PAULICS, Veronika. Disseminação de inovações em gestão local. In: COLÓQUIO INTERNACIONAL DE PODER LOCAL: DESENVOLVIMENTO E GESTÃO SOCIAL DE TERRITÓRIOS, 10., 2006, Salvador. Anais... Salvador: UFBA/CIAGS, 2006, BA, CDROM. (2006).

PROGRAMA GESTÃo PÚBLICA E CIDADANIA. Histórias de um Brasil que funciona, Diversas edições. São Paulo: Programa Gestão Pública e Cidadania, 2000-2005.

ROGERS, Everett. The diffusion of innovation. New York. Free Press, 1995..

ROSE, Douglas D. National and local forces in State politics: the implications of multi-level policy analysis. The American Political Science Review, v. 67, n. 4, 1973, p. $1162-1173$.

ROSE, Richard. What is lesson drawing? Journal of Public Policy, v.11, 1991, p. 3-30. SOUZA, Celina; CARVALHO, Inaiá M. M. Reforma do Estado, descentralização e desigualdades. Lua Nova, 48, 1999. p. 187-213.

SPINK, Peter; CLEMENTE, Roberta (org.). 20 Experiências de gestão pública e cidadania. Rio de Janeiro: Editora Fundação Getulio Vargas, 1997.

SPINK, Peter. The rights approach to local public management: experiences from Brazil. Revista de Administração de Empresas, 40, p.45-65, 2000.

SPINK, Peter. A inovação na perspectiva dos inovadores. JACOBI, Pedro e PI$\mathrm{NHO}$, José Antonio. Inovação no campo da gestão pública local: novos desafios, novos patamares. Rio de Janeiro: Editora FGV, 2006. p. 23-41.

SUGIYAMA, Natasha Borges. Ideology \& networks: social policy diffusion in decentralized Brazil. Paper delivered at the 2006 Meeting of the Latin American Studies Association. San Juan, Puerto Rico, March 15-18, 2006.

SUGIYAMA, Natasha Borges. Political incentives, ideology and social networks: the diffusion of social policy in Brazil. Paper delivered at the 2004 Meeting of the Latin American Studies Association. Las Vegas, Nevada, October7-9, 2004. 
TEIXEIRA, Marco Antonio Carvalho; GODOY, Melissa G. de; CLEMENTE, Roberta. 20 Experiências de gestão pública e cidadania - ciclo de premiação 2005. São Paulo: Programa Gestão Pública e Cidadania, 2005.

UNDESA. Ad hoc Expert Group Meeting on Approaches and methodologies for the assessment and transfer of best practices in governance and public admnistration. Aide Memoire. Tunis, Tunisia, 13-14 June 2005.

UNDESA. Innovations in Governance and Public Administration: replicating what works. United Nations. Department of Economic and Social Affairs. New York, 2006 (Adriana Alberti and Guido Bertucci (org.). http://www.unpan1.un.org/

WALKER, Jack L. The diffusion of innovations among the American States. American Political Science Review, v. 63, n.3, 1969.

WAMPLER, Brian. The diffusion of participatory budgeting in Brazil. Paper delivered to Lasa 2004 - Latin American Studies Association Meeting, Las Vegas, Nevada, October 7-9 2004. (Draft version)

WEYLAND, Kurt. Learning from foreign models in Latin American Policy Reform: an introduction. In: WEYLAND, Kurt (ed.). Learning from foreign models in Latin American policy reform. Washington DC: Woodrow Wilson Center Press, 2004. 